\title{
Ordem e desordem nos labirintos da ficção: os bibliotecários e suas representações em alguns produtos culturais contemporâneos
}

\author{
Order and disorder in fiction labyrinths: the librarians' \\ representations in some contemporary cultural productions
}

Giulia CRIPPA'

\begin{abstract}
RESUMO
Este trabalho, primeiro resultado de uma pesquisa mais ampla, propõe uma indagação sobre alguns aspectos das representações sociais de bibliotecas e bibliotecários em produções literárias e cinematográficas. Surgida com finalidades catalográficas, aos poucos essa indagação revelou elementos que estabeleciam séries diversas, em que o gênero narrativo, tanto literário como cinematográfico, não resultava relevante em relação à representação da biblioteca e do bibliotecário. A presença desses elementos aparenta evidenciar algumas expectativas e utopias em relação ao conhecimento independentemente das narrativas serem ambientadas no passado, no presente ou no futuro, estimulando uma reflexão sobre algumas tradições medievais e barrocas relativas ao universo das bibliotecas e de seus protagonistas, os bibliotecários. Os materiais utilizados foram os filmes "A máquina do tempo", "Farnheit 451", "O dia depois de amanhã", "Star Wars - A Guerra dos clones", e os romances "Martin Éden", "O homem sem qualidades", "A máquina do tempo" e "A sombra do vento".
\end{abstract}

Palavras-chave: biblioteca; bibliotecário; imaginário; cinema; literatura.

\begin{abstract}
This paper, first result of a larger research, proposes a query about some aspects of social representation of libraries and librarians, as they appear in literary and cinematographic productions. Little by little, this query, which arose from purposes of organizing catalogues, revealed elements that established different series, in which the narrative genre (literary or cinematographic) has no relevance to either libraries or librarians' representations. The presence of these elements seems to show some expectations and utopias in relation to the common knowledge, independently from narratives being located in the past, in the present or in the future, stimulating reflection on some medieval and baroque traditions about the library universe and its main characters, the librarians. The cinematographic material selected for research was The time machine, Farenheit 451, The day after tomorrow, Star Wars - episode II and the novels Martin Eden, The man without qualities, The time machine and La sombra del viento.
\end{abstract}

Keywords: library; librarian; imaginary; cinema; literature.

1 Doutora em História Social, Universidade de São Paulo, USP, Brasil. Docente do Curso de Ciências da Informação e da Documentação, Faculdade de Filosofia Ciências e Letras de Ribeirão Preto, Departamento de Física e Matemática, Universidade de São Paulo, USP, Ribeirão Preto, SP, Brasil. Av. dos Bandeirantes, 3900, Monte Alegre, 14040-901, Ribeirão Preto, SP, Brasil. E-mail: <giuliac@ffclrp.usp.br>.

Recebido em 28/2/2008 e aceito para publicação em 10/6/2008. 


\section{INTRODUÇÃO}

Espelho de Mnemosyne, lugar de diálogo incessante com o passado, a imagem da biblioteca percorre a textualidade ocidental com a vitalidade de uma tópica constante. A partir do Dom Quixote, a biblioteca torna-se um lugar determinante nos acontecimentos de muitas narrativas. Por meio de sua presença, é possível encontrar as transformações e persistência que permeiam sua identidade, especialmente ao longo da Modernidade, quando se estabelece uma dialética inquieta entre utopias de preservação e disseminação universais, frequentemente relacionada às Tecnologias de Informação e Comunicação (TICs) e a tradição, inteiramente humanista, da melancolia barroca que medita sobre a inevitabilidade do esquecimento e da ruína.

A biblioteca, equipamento cultural enquanto destinada a práticas culturais, seja ela tangível ou desmaterializada no fluxo de dados de rede, é um dos lugares indispensáveis onde o conhecimento se concretiza em suas formas físicas, uma verdadeira máquina capaz de transformar crenças em conhecimentos (Coelho, 1997). O conhecimento, todavia, não é dado, mas é o resultado de uma construção ligada à seleção e à ordem dada a seus resultados, e o bibliotecário torna-se um dos seus arquitetos, em constante mutação: ele constrói a coleção como uma estrutura através da qual o leitor deve circular, reconhecer-se, viver. Toda biblioteca é resultado de uma escolha e, realizando essa escolha, o bibliotecário transforma-se no seu primeiro autor. Se o exercício de sua profissão já impõe tamanha responsabilidade "autoral", se complica ainda mais na medida em que encontra sua função nos opostos de conservação e de disseminação para o público: ambos os atos supõem um catálogo, mas sua configuração em função da conservação torna-se, por exemplo, uma escolha imposta ao leitor.

De maneira geral, observa-se, na literatura da área de biblioteconomia, a tentativa de desenhar figuras profissionais capacitadas em trabalhar com as representações dos objetos e em criar mecanismos para localizar a informação, de maneira rápida e eficaz (Barros, 2003; Borges, 2004; Marquetis, 2005; Ortega y Gasset, 2006).

Para o termo bibliotecário define-se, aqui, um profissional que opera um conjunto de funções que tornam necessário o uso da palavra no plural, tanto no âmbito de um ambiente de biblioteca tradicional, como pelas inovações provocadas pelo uso das TICs. Valentim (2002, p. 1 19) sublinha que "a preocupação com a auto imagem [...] é fundamental para a imagem do profissional na organização em que está atuando". Estamos perante um "imaginário profissional" compreendido entre a tradição ligada à materialidade do livro e ao espaço físico das bibliotecas de um lado, e a realidade da informação desmaterializada, que se torna virtual, disponibilizada em bancos de dados em rede, de certa forma instantânea e, em muitos casos, global$^{2}$.

O leitor, hoje definido com o termo usuário, outro protagonista da biblioteca, goza, por sua vez, de um status em geral pouco percebido: o do anonimato solitário, desolador, que faz com que, paradoxalmente, - bibliotecário conheça mal o seu público. Para conhecer seus leitores, ele dispõe de duas metodologias: por um lado, as estatísticas que the podem revelar que o público é composto mais de mulheres que de homens, ou mais de pesquisadores do que de iletrados, algo que, de fato, iá é conhecido; por outro lado, pode realizar trocas pessoais que o levam a um tratamento diferenciado mas, quantitativamente muito limitado das exigências dos usuários. Nenhum dos dois caminhos parece plenamente satisfatório e a biblioteca, aparentemente um serviço para todos, na realidade torna-se, com frequência, um lugar onde cada um deve poder se salvar sozinho. O bibliotecário, para o leitor, torna-se uma presença, um olhar, um ouvido mais ou menos distante ou prestativo. Poucas figuras de bibliotecário tornaram-se famosas pela sua atuação mas, muitos protagonistas da cultura literária e filosófica a tiveram. É o caso, por exemplo, de Anatole France, bibliotecário do Senado, ou de Georges Bataille, que atuou em Orleans. Ainda, poucos lembram o ofício de Leibniz como bibliotecário do duque de Hannover, de Lessing, na fabulosa biblioteca de Wolfenbuttel, ou de

2 Consideramos interessante o entrelaçamento entre a realidade das TICs e o espaço utópico que permeia as discussões na área, como, por exemplo, ALVARENGA, Eliany Araújo; DIAS, Guilherme Atayde. A atuação profissional do bibliotecário no contexto da sociedade da informação. In: OLIVEIRA, Marlene de (Org.). Ciência da informação e biblioteconomia: novos conteúdos e espaços de atuação. Belo Horizonte: UFMG, 2005, p. 114, onde os autores incluem, em uma lista de novas tecnologias: "têm se destacado os decodificadores digitais" [grifo nosso], especificando que estes "ainda não existem". 
Goethe, em Weimar. Robert Musil, que em seu "O homem sem qualidade" oferece uma das mais brilhantes fotografias das contradições das bibliotecas como bibliotecário na Escola Politécnica de Viena de 1911 a 1914.

Enquanto tentativas de desenhar o leitor ideal o destacam como agente possível, um bibliotecário ideal é impossível de se identificar em uma única figura.

Neste artigo propomos uma indagação sobre alguns aspectos das representações sociais de bibliotecas e de bibliotecários, documentadas em uma pequena amostra de produções literárias e cinematográficas. Observam-se, em um primeiro levantamento, séries de elementos sobre o tema da biblioteca e do bibliotecário - de maneira independente do gênero narrativo, tanto literário como cinematográfico - que contribuem para delinear retratos tanto de um como do outro, provocando reflexões dispostas em ensaio quase barroco sobre o conhecimento e seus tutores.

Uma análise de ficções literárias e de cinema, produtos de uma cultura de massa cuja circulação envolve, no caso dos filmes, ampla reprodução doméstica, permitem-nos mostrar algumas características que atribuímos, hoje, principalmente nas narrativas hollywoodianas, aos ambientes e aos profissionais da informação.

Filmes e livros produzidos para um mercado amplo encontram seu público na medida em que lhe fornecem "retratos" idealizados e, ao mesmo tempo, que podem ser associados à experiência, reconhecidos. Entre os inúmeros livros e filmes que oferecem imagens de bibliotecas e de bibliotecários, selecionamos alguns que esboçam uma gama ampla de "variações sobre o tema". Nesse trabalho, não foram selecionados livros ou filmes que apresentam o bibliotecário e a biblioteca como protagonistas, como no caso, por exemplo, do clássico "O nome da Rosa" (1986). Escolhemos produtos em que esse tema está à margem, aparece como episódico ou secundário em relação à dinâmica das narrativas, como no caso de "Martin Éden."

\section{"POSSO AJUDAR?": UM BIBLIOTECÁRIO E UM USUÁRIO SATISFEITO.}

Martin Éden tem uma dúvida: qual das bibliotecas públicas, disponíveis na São Francisco da virada do século XIX, frequentar para iniciar sua educação. Resolve entrar na biblioteca de Oakland, pois se encontra mais próxima da residência de Miss Ruth, uma jovem abastada pela qual o marinheiro protagonista do romance de Jack London se apaixonou. Martin, que tem uma extraordinária paixão pelos livros, mas conhecimentos limitados para aproveitar seu conteúdo, está em busca de um livro de boas maneiras, para aprender as normas de comportamentos adequadas ao ambiente burguês a que Ruth pertence, bem diferente do dele.

Perdido no labirinto das estantes, cuja ordem dos conteúdos ele desconhece, identifica na jovem "de traços finos, que parecia uma francesa", uma assistente de biblioteca, que o encaminha ao serviço de referência, onde está o bibliotecário, sentado atrás de uma mesa. Martin Éden, todavia, resolve percorrer as estantes sozinho, procurando uma trilha que o leve àquele livro desejado, cujo conteúdo ele procura, dentro daqueles milhares de volumes.

Ouvira falar dos livros de filosofia, mas nunca imaginara que tantos livros foram escritos sobre o assunto. As outras estantes, carregadas de pesados volumes, o humilharam e, ao mesmo tempo, estimularam. Aí havia trabalho para o vigor de seu cérebro. Encontrou livros de trigonometria na seção de matemática, e virou suas páginas, olhando para as fórmulas e números incompreensíveis. Sabia ler inglês, mas o que via ali era uma linguagem estrangeira. [...] Desesperado, deixou a seção. Por todos os lados, os livros pareciam apertá-lo e espremêlo. Nunca sonhara que a disponibilidade do conhecimento humano fosse tamanha. Estava apavorado. Como poderia assimilá-lo todo? [...] Assim continuou perambulando, passando da aflição ao entusiasmo, conforme observava as prateleiras recheadas de sabedoria. [...] Deu uma olhada em volta da sala e fechou as pálpebras sobre a visão de dez mil livros (London, 2004).

A primeira experiência em uma biblioteca pública termina sem que Martin consiga satisfazer, nessa andança desordenada, sua busca pelo manual de boas maneiras. Todavia

Encontrou o que procurava? - perguntou-lhe o homem da mesa, enquanto saia. - Sim senhor, - respondeu. - É uma biblioteca bonita, essa. - 
O homem acenou afirmativamente. - Ficaremos felizes em ver o senhor com frequência. $O$ senhor é marinheiro? - Sim senhor, - respondeu. - e voltarei. 'Como descobriu? se perguntou, descendo as escadas (London, 2004).

Esse senhor, do qual nenhuma descrição nos é fornecida, revela grandes capacidades de entender as exigências de Martin, suscitando sua admiração; ele começa a frequentar a biblioteca regularmente, começando a ler tudo que lhe cai nas mãos. Infelizmente, porém,

Os muitos livros que lia só faziam aguçar o interesse dele. Cada página de cada livro era uma fenda que se abria no reino do saber. Sua fome se alimentava do que ele lia, e aumentava. Ainda, ele não sabia por onde começar, e sofria continuamente pela falta de preparo (London, 2004).

Apesar disso, as leituras que realiza, ainda que confusas, o estimulam a refletir sobre as discussões que ouve, discussões que o levam de volta, atormentado pelas dúvidas, à biblioteca, onde, no entanto, "O homem da mesa da biblioteca vira Martin com tanta frequência que se tornara cordial, e sempre o cumprimentava com um sorriso e um aceno". A gentileza do bibliotecário aproxima Martin até criar coragem para pedir aquela informação que, afinal, o levara para esse mundo novo da biblioteca, a resposta que, até aquele momento, não encontrara no seu caminho pelas estantes, ou seja: quando um jovem é convidado por uma senhorita a visitá-la, quando pode ir?

Encontramos, aqui, um retrato muito positivo de bibliotecário de referência capaz de fornecer ao usuário a informação procurada:

Aquela garota é feita como não sou feito eu, e eu sou feito como ela não é feita. $O$ senhor não acha que estou bancando o tolo, não é? perguntou de repente [Martin]. - Não, não, de jeito nenhum! - protestou o outro. - Seu pedido não é exatamente do âmbito do serviço de referências, mas ficarei bem feliz em poder ajudar o senhor. - Martin olhou-o com admiração. [...] - Faça o seguinte, - disse o bibliotecário iluminando-se - ligue para ela e pergunte! [...] (London, 2004).
Nessas poucas páginas, de um bem mais amplo romance de formação parcialmente autobiográfico, encontramos uma figura e um ambiente que modulam e recalcam expectativas e mudanças na ordem da representação de um dos principais mediadores entre o livro/texto e seu publico leitor, o bibliotecário.

\section{O PERFEITO BIBLIOTECÁRIO DESSE MUNDO FUTURO: TRANSFORMAÇÕES IDEOLÓGICAS}

Em 1898 nascia, da pena de H.G.Wells, a fantasia de uma máquina do tempo, capaz de transportar o cientista inventor para o passado e o futuro. Após uma versão para o cinema em 1960, com o mesmo título "The time machine" (A máquina..., 2002), a novela foi novamente adaptada em 2002, em uma produção que modifica alguns aspectos ideológicos da história original em relação à representação da biblioteca que o autor oferece.

A ação inicial se desenrola no gabinete de um cientista, Alexander. Identificamos o espaço de um estudioso pelas marcas cenográficas da parede coberta de livros, da lousa coberta de cálculos, dos alambiques e provetas. $\bigcirc$ protagonista está envolvido na construção da máquina que permitirá seu deslocamento temporal. Depois de descobrir que a volta ao passado não modifica os efeitos dos eventos, resolve avançar no futuro. Sua primeira parada é no ano 2030. O mundo, muito parecido com o nosso, é iluminado por enormes painéis digitais de propaganda da colonização lunar, próxima a acontecer, graças a enormes explosões sublunares. Curioso, Alexander desce de sua máquina e entra no prédio mais próximo, cuja placa avisa tratarse da biblioteca pública.

A arquitetura externa dessa biblioteca remete à tradição neoclássica americana do século XVIII. Seu interior, todavia, contrasta com essa aparência tradicional. Uma rápida panorâmica revela um ambiente vivaz e, ao mesmo tempo, "vazio". Há poucos livros, e eles parecem desempenhar muito mais uma função expositiva do que de uso. De fato, descobrimos logo que todos os livros já foram digitalizados e depositados em grandes bancos de dados conectados em rede no mundo inteiro.

Quem nos informa disso é Vox, uma "unidade fotônica de terceira geração com funções verbais e 
visuais, conectada a todos os bancos de dados" (A máquina..., 2002). Vox encarna, ao mesmo tempo, a biblioteca e seu bibliotecário, pois o acesso ao conteúdo dos livros é possível somente por meio da interface por ele representada e que, perante os pedidos do usuário, abre os "arquivos" que contêm a informação. Apesar de sua grande disponibilidade, Alexander não encontra nenhuma informação cientificamente válida em sua busca pelo assunto "viagem temporal". Vox realiza a utopia de um bibliotecário/biblioteca que compreende o sonho do acesso instantâneo à universalidade de todos os registros possíveis.

O segundo encontro entre Alexander e Vox traz uma referência interessante. A lua, fragmentada pelas explosões, provoca um imenso desastre na terra. Vox reconhece Alexander, ainda que meio século tenha se passado desde o primeiro encontro, e o convida a buscar refúgio do desastre. No ato da despedida, levanta a mão em uma saudação popular para o público de seriados cult da TV, a saudação do alienígena vulcano Mr. Spock, protagonista de Star Trek, seriado norteamericano da década de 1970. Spock é o oficial de ciências da nave estrelar Enterprise, um bibliotecário de referência ideal capaz de encontrar a informação necessária nos bancos de dados humanos e alienígenas. Reconhecemos, assim, a utopia de um saber ilimitado baseado e uma noção de senso comum da ciência.

O terceiro encontro entre os dois acontece no ano 802.701. A terra, depois do desastre, regenerouse, e duas raças convivem nela, os Elois e os Morlocks. Enquanto os primeiros, de aspecto humano, vivem pacificamente e em harmonia, os segundos são o resultado de uma mutação monstruosa e vivem em cavernas subterrâneas, alimentando-se da carne dos Elois.

Para entender o que aconteceu depois do desastre, Alexander vai até um lugar que os Elois dizem ser habitado por fantasmas. Na verdade, algo sobreviveu à destruição: Vox, que graças às inesgotáveis reservas de energia ainda está ativo. A memória da antiga biblioteca pública manteve-se intacta, apesar da destruição de todos os livros.

É nesse ponto que a adaptação cinematográfica desvia, de maneira evidente, da narrativa de Wells. No romance, o protagonista encontra os vestígios da biblioteca:

Reconheci imediatamente nos trapos escuros e queimados pendurados nas paredes os restos dos livros. Há muito tempo estavam em peda- ços, e todo vestígio de impressão desaparecera; mas aqui e acolá havia tábuas curvadas e ganchos quebrados de metal muito significativos. Se eu fosse um letrado, poderia, talvez, moralizar sobre as ambições humanas. A coisa que mais me chocou, todavia, foi o enorme desperdício de esforço que aquela triste e desoladora paisagem de papel apodrecido testemunhava (Wells, 2004).

Vox, pelo contrário, está em pleno funcionamento, ainda que os vestígios de livros apareçam na cenografia, fragmentando-se ao toque de Alexander. Todavia, Vox é a memória de um passado que é capaz de satisfazer somente em parte as exigências do protagonista. De fato, seu "acervo" não contempla um conhecimento completo dos acontecimentos depois da destruição pois, como ele mesmo afirma, não foi alimentado, faltaram-Ihes as fontes. Somente um Eloi, que conseguiu fugir da caça dos Morlocks, forneceIhe algumas breves notícias sobre as duas raças.

$\mathrm{Na}$ conclusão do filme, a imagem de Vox aparece como "voz da memória", enquanto narra às crianças um dos romances contidos em seu banco de dados, "Tom Sawyer". Uma citação, talvez do livro (Bradbury, 1953) (e filme) "Fahrenheit 451" (1966), em que os homens, depois da destruição atômica da civilização, movimentam-se por uma floresta, cada um encarnando um livro.

O final de "Fahrenheit 451", por sua vez, remete à "Divina Comédia" (Alighieri, 2005?) dantesca, com sua selva escura em que o poeta se perdeu. Dante chega até a base do monte do purgatório, mas sua subida lhe é impedida por três feras. É quando o poeta Virgílio aparece para conduzi-lo pelo reto caminho destinado a levá-lo até Deus. Virgílio será o guia que o levará pelos lugares onde o conhecimento é criação humana, o Inferno e o Purgatório.

Nesses lugares, Virgílio se torna o "bibliotecário" que apontará aquilo que é disposto nesse grande "teatro da memória" que são as estruturas do Inferno e do Purgatório, nos quais as paixões e os pecados são atrelados, com frequência, às palavra de poetas, escritores, personagens e leitores de livros.

\section{VIRGÍLIO: METÁFORA DO BIBLIOTECÁRIO.}

De um verdadeiro Virgílio se trata, quando encontramos uma biblioteca chamada "Cemitério dos 
livros esquecidos", e seu bibliotecário, Isaac, em um romance contemporâneo: publicado originariamente em 2001, "La sombra del viento", de Carlos Ruiz Zafon (2004), desenvolve seu enredo em volta de dois protagonistas: um livro e seu leitor. $\bigcirc$ encontro entre os dois acontece desde o primeiro capítulo, em uma biblioteca secreta, ainda que aberta a leitores fiéis, chamada "Cemitério dos livros esquecidos". $\bigcirc$ jovem Daniel chega a ela por intermédio do pai que, antes de bater no portão, recomenda que o filho mantenha o segredo sobre esse lugar. Quem abre a porta, o guardião/bibliotecário, Isaac, é "um homenzinho com cara de ave de rapina e cabelos prateados", seu olhar é impenetrável. A biblioteca apresenta-se como "Um amplo salão circular, coberto por uma cúpula da qual descem lamas de luz" (Zafon, 2004, p.9). Segue uma série de metáforas que constroem o ambiente:

um templo tenebroso, um labirinto de plataformas com estantes altíssimas cheias de livros, uma colméia enorme percorrido por túneis, escadas, [...]. Uma biblioteca gigantesca de geometrias impossíveis (Zafon, 2004, p.64) [tradução nossa].

Essa biblioteca/cemitério tem a função de preservar aqueles livros desaparecidos, esquecidos, perdidos, em um estado de "animação suspensa", à espera de um leitor que lhes devolva a vida plena. A tradição do lugar pede que todos os "novatos" do lugar adotem um livro, devolvendo-o à vida. E assim, o jovem Daniel encontra o romance protagonista: um romance que alguém quer destruir, e Daniel "inventa" a maneira para pô-lo a salvo, escondendo-o dentro da biblioteca/ cemitério, no meio de outros livros. Assim, uma noite, Daniel volta ao lugar e explica para Isaac que precisa esconder o livro. $\bigcirc$ bibliotecário, apesar de responder que "Este é um cemitério, não um cofre" (Zafon, 2004, p.64), o deixa entrar e abre a engrenagem que permite o acesso à biblioteca, onde entram ambos. $\bigcirc$ bibliotecário é descrito como alguém entre "Carão e o bibliotecário de Alexandria" (Zafon, 2004, p.64), figura que afirma que "aqui dentro sou eu quem impõe as regras" (Zafon, 2004, p.65), mas essa impressão de rigidez e severidade logo deixa espaço a "um sorriso maroto: Isaac divertia-se em interpretar seu papel de Cérbero"(Zafon, 2004, p.65). Uma figura aparentemente pouco simpática, mas na realidade preocupada com o destino do livro, a ponto de sugerir como escondê-lo sem perder seus vestígios no labirinto das estantes, para conseguir, em seguida, recuperá-lo:

\begin{abstract}
'Pensa em voltar para recuperá-lo, em algum momento?' perguntou. 'Com certeza'. 'Então, poderia recorrer a um pequeno truque' [...]. 'Meu jovem, [...], pense no Minotauro'. [...] Tirou do bolso um velho canivete, que me ofereceu. 'Faça uma marca toda vez que virar de corredor, uma marca que somente você possa reconhecer. É uma madeira tão velha e cheia de arranhões que somente quem sabe o que procurar perceberia" (Zafon, 2004, p.73).
\end{abstract}

Assim, o livro fica dentro da biblioteca, aparentemente confuso no meio de um conjunto de textos sobre "alienação de bens", perdido no labirinto, aparentemente fora de uma ordem lógica, mas, na verdade, possível de ser recuperado pelo protagonista em qualquer momento, seguindo a marcação que ele designou. Assim como em Martin Éden, a biblioteca/ cemitério de Zafón se apresenta como lugar em que o sentido e a ordem pertencem ao bibliotecário, lugar onde o usuário/leitor encontra seus caminhos por meio de seu guia. As metáforas "infernais" utilizadas, de Cérbero e de Carão, notáveis "guardiões" dantescos, são aplicadas à figura de um bibliotecário, mas atrás dessas personae transparecem, como "sorriso maroto", as feições de Virgílio, que, também, por meio de sua sugestão de encontrar um caminho específico de ordem no labirinto - a marcação com o canivete na madeira das estantes - desempenha suas funções tanto de guardião (o livro fica protegido) como de facilitador/ mediador que indica as ferramentas de uma nova, possível ordem: não é ele que esconde o livro, mas é ele que sugere como fazê-lo.

Consideramos, novamente, o romance original de Wells: o protagonista entra na biblioteca destruída e se encontra cercado pela podridão dos livros. À descrição segue uma consideração moralizadora em que afirma, digno êmulo de uma tradição literária de melancolia, que todo aquele saber representa um desperdício.

Observemos algumas pinturas do século XVII, Naturezas Mortas, para descobrir que a máquina do tempo, quando chega a esse futuro de destruição, alimenta-se, na verdade, de um rico e já esquecido passado: uma mesa, livros estragados, consumidos, desordenados, inúteis. Naturezas Mortas representando 
livros são emblemas de ordem moral: alertas contra a vaidade do conhecimento humano, destinado a perecer, em todo caso. São inúmeras as pinturas, produzidas ao longo do século XVII, que convidam os espectadores a uma reflexão sobre a caducidade humana, através de conjuntos de objetos artificiais ou naturais. Entre eles, os livros parecem ter um papel garantido, associando-se ao pecado do orgulho que, como sabemos, provocou a queda de Lúcifer, de Adão e Eva e destruiu a torre de Babel, somente para citar alguns dos efeitos mais conhecidos desse pecado.

Vamos tentar entender as razões disso: a escrita, desde sua invenção, modificou as formas de pensamento e de expressão. Por sua vez, a tecnologia da impressão teve efeitos diversos e profundos, desde a disseminação e reorganização dos sistemas dos saberes até a constituição de uma economia capitalista. Como todas as revoluções, essa também encontrou fortes resistências. $\bigcirc$ grande aumento nas tiragens permitiu uma propagação da informação até então impossível, que abriu o caminho a idéias democráticas: a educação, de fato, pode alcançar partes mais amplas da população. É uma tendência que provoca reações preocupadas por parte de autores conservadores, os quais, apesar de abertos às idéias humanistas, continuam apoiando o sistema tradicional de valores feudais.

Vários estudos mostram como, no começo do século XVII, o interesse pela leitura cresceu. Não somente novos títulos eram publicados mas, o nível de acesso às obras torna-se mais amplo, graças à circulação de coleções de custo menor. É uma mudança que acompanha a crescente tendência à secularização, que desenvolve alternativas à oferta de obras de caráter religioso que dominara até então.

Esse processo de transformação provocou uma onda de insegurança entre os teólogos de orientação conservadora, entre os humanistas e os artistas, que passaram a considerar os livros como luxo supérfluo. Aos que afirmavam que os livros eram registros permanentes e imutáveis da experiência e do conhecimento humanos, era lembrado seu caráter efêmero. Enquanto a população européia dobrava entre 1500 e 1600, a produção de livros cresceu dez vezes mais. Em sua "Anathomy of Melancholy", Robert Burton (2005, p.77) escreve que "já temos um caos enorme e uma confusão de livros. Somos por eles subjugados e nos doem os olhos pela leitura e os dedos por virar as páginas", assim como Barnaby Rich já tinha escrito, em 1600, que a grande quantidade de livros era, na sua época, um dos flagelos da humanidade. A reflexão moralizadora sobre os livros encontra-se, ainda, em Goethe, que, já no final do século XVIII, em um comentário sobre as obras de Shakespeare, compara os cuidados das edições nos primeiros tempos do livro impresso com o desleixo editorial de seus tempos.

A proliferação dos livros é, portanto, vista como um excesso, provocando reações de cunho moral e reflexões melancólicas sobre as vaidades humanas, a ponto de sua representação na pintura integrar o tema do Memento Mori. Observado no âmbito dessa tradição, Wells esboça uma Natureza Morta literária com livros e considerações moralizadoras, de gosto barroco, sobre a vaidade humana. Da mesma maneira, poderíamos entender a presença dos humanos/livros no bosque fora da cidade destruída pela catástrofe tecnológica do conhecimento desenhada por Bradbury: uma Natureza Morta literária com livros, onde os temas clássicos da melancolia barroca se reformulam.

A versão cinematográfica da obra de Wells nos mostra a sutil e todavia consistente transformação que essa tradição melancólica atravessou, graças ao sonho tecnológico que realiza um novo estado edênico. Vox possui um saber universal, que o aproxima da esfera do divino. Se a tradição judaico-cristã desenrola-se por meio da fé no livro divino transcrito para a humanidade, um livro/biblioteca que, ao longo do tempo, representou o conhecimento supremo, também essa biblioteca/bibliotecário contém tudo em sua memória. Vox, a voz, princípio primeiro da criação, é a antítese da Natureza Morta com livros que o autor escreveu.

Vox não é humano, sabemos tratar-se de uma memória artificial. Um substituto mais ou menos eterno dos livros e de seu administrador e mediador, o bibliotecário, capaz de conter o universo.

Seu contrário é um arquivo/biblioteca e sua bibliotecária, como são retratados no segundo episódio da epopéia de "Star Wars: a guerra dos clones" (2002). Em uma sequência se mostra a busca sem resultados do cavaleiro Jedi Obi-Wan Kenobi para localizar um planeta distante. Obi-Wan entra na enorme sala do arquivo galáctico, em que não há livros, mas feixes de luz que geram os hologramas da informação desejada. É recebido por uma bibliotecária que lhe "abre" o acesso aos arquivos em uma mapoteca virtual. 
planeta, todavia, não aparece em lugar nenhum. Insatisfeito, Obi-Wan pergunta para a bibliotecária onde se encontra essa informação. A resposta remete, infelizmente, a um certo estereótipo de bibliotecário pouco disponível para as exigências do usuário e ciumento do patrimônio que controla: se o planeta não aparece nos registros, então ele não existe.

A economia narrativa do filme não necessita da presença dessa sequência, pois a ação se desenrola de forma disjunta do episódio. E é essa natureza episódica que a torna interessante em termos de representação da biblioteca e de seu guardião. Porquanto fantasiosa e ficcional seja essa biblioteca, um verdadeiro palácio/templo, um museu/mausoléu, algumas questões permanecem implícitas: sua capacidade universal de conter todos os saberes é desafiada, ambição que, desde a construção do mito da biblioteca de Alexandria, se perpetua nas visões literárias e tecnológicas até os nossos dias.

É a arrogância dessa universalidade fictícia que transparece nas palavras ofendidas da bibliotecária, incapaz de aceitar e reconhecer os limites dos registros. A biblioteca declara, nesse caso, sua própria inutilidade e a bibliotecária transforma-se em uma presença hostil, cuja gentileza é somente formal e a atividade ineficaz. Observa-se aqui um retrato/estereótipo das funções de uma biblioteca que preserva e fornece automaticamente um saber institucionalizado em que se deve acreditar cegamente, enquanto representação fiel e espelho do mundo e do universo.

No caso de "A máquina do tempo" observamos a realização da utopia que integra biblioteca e bibliotecário em um suporte praticamente eterno da memória; em "Star Wars", por outro lado, esse pequeno episódio nos mostra, camuflada de fábula fantasy, seu contraponto. Em ambos os casos, todavia, tanto o ambiente como seu representante operam principalmente na vertente que o senso comum lhes atribui: encontrar e disponibilizar (ou não) uma informação que o usuário precisa para solucionar um problema.

\section{A BIBLIOTECA COMO METÁFORA DA DIALÉTICA CULTURA/NATUREZA.}

Diferente é o caso da biblioteca real que aparece no filme "O dia depois de amanhã" (2004), a Public
Library of New York, protagonista dessa produção de gênero catastrófico de 2004.

Por causa do efeito estufa, o mundo atravessa uma repentina mudança climática, durante a qual se instaura uma nova era do gelo. O protagonista, especialista em expedições polares, procura alcançar e resgatar o filho, preso nos gelos que cobriram a cidade e que encontrou refúgio, com alguns outros sobreviventes, justo nas salas da biblioteca. Os desafortunados hóspedes desse ambiente sobrevivem em uma sala cuja lareira queimará, inevitavelmente, os livros contidos na biblioteca. A bibliotecária, fiel aos princípios conservativos de sua profissão, tenta oporse mas, perante a necessidade de sobreviver, ajuda a acender o fogo. Na cena seguinte, há uma discussão entre duas personagens sobre a seleção dos livros a serem queimados, e Nietzsche, filósofo controvertido, pode ser uma das vítimas das chamas. Todavia, a proposta de queimar os livros de contabilidade tributária é aceita, e Nietzsche está a salvo da fogueira. Digressão interessante, especialmente à luz dos problemas que, cada vez com mais frequência, envolvem a seleção dos livros nas bibliotecas reais, que enfrentam pressões políticas ou religiosas nas suas aquisições.

Talvez a ideia de eliminar aquilo que não provoca discussão aliviaria também as bibliotecas da manutenção de milhares de livros que, como os manuais de informática, por exemplo, são constantemente atualizados, tornando-se logo inúteis no espaço que ocupam. Estariam a salvo da destruição tanto os amigos como os inimigos das modernas democracias, pois provocam discussões.

Boa parte do filme é ambientada no interior da biblioteca, e, talvez, seja necessário "esquecer" o enredo principal e procurar uma Natureza Morta fora e dentro dessa biblioteca pública. Em primeiro lugar, representa a salvação para aqueles que resolvem nela permanecer. Após a inundação que cobriu a cidade, a maioria das pessoas que se refugiara na biblioteca resolve procurar ajuda saindo. Não se sabe para onde, mas o espectador está a par de que sair significa a morte, coisa que, de fato, é mostrada. Por outro lado, o fogo produzido pelos livros que queimam na lareira da biblioteca aquece os refugiados, garantindo sua sobrevivência, até o resgate chegar. A biblioteca e todo conhecimento nela contida estão congelados, com exceção daqueles que, materialmente, queimam, preservando a vida. Alguma coisa, porém, será resgatada do gelo e do fogo: o 
Livro Mestre, a Bíblia de Gutemberg, tanto espiritualmente, enquanto "livro biblioteca" quanto "tecnologicamente" enquanto primeiro livro impresso no Ocidente e símbolo de "modernidade científica".

A bibliotecária é delineada como uma profissional aparentemente pouco simpática mas, na verdade é essencial para que esses usuários involuntários da biblioteca se salvem. Logo após a inundação, ela se senta à sua mesa, observando silenciosamente que, apesar da situação, ninguém provoque estragos. Apesar dessa supervisão, cômica dentro da situação, é capaz de reconhecer a necessidade, que a mantém calada na frente dessa humanidade molhada e espantada. Essa bibliotecária não abandona seu lugar, e continua seu trabalho de serviço de referência, muito próximo, em sua essência, ao do bibliotecário sem rosto de "Martin Éden" (London, 2004): é ela que sabe onde estão a sala com lareira, os distribuidores automáticos de chocolate e biscoitos, a comida necessária à sobrevivência. Ainda que se oponha à fogueira dos livros, sua resistência é uma formalidade. Seu rosto não é marcante, mas seu papel é coerente com sua função ao longo do filme: fornece informação aos seus peculiares usuários para que eles encontrem a solução de seus problemas.

A biblioteca, como lugar de ordem, adquire, de fato, um papel protagonista na colocação ideológica do filme na medida em que estabelece continuamente uma dialética com a natureza selvagem e descontrolada que significa morte. A ordem opõe-se à desordem, ainda que na destruição dos livros que, de fato, só adquirem importância pela sua materialidade e não pelo conteúdo. Eles se salvam porque existem fisicamente.

Observa-se, nessa pequena amostra, um leque possível de representações em que a biblioteca, como protagonista ou como episódio, apresenta-se nas duas vertentes de lugar de salvação e de orgulho, nisso perpetuando suas interpretações mais antigas. Lugar de salvação na "A máquina do tempo" e no "Dia depois de amanhã", assim como em "Martin Éden". O tema da perda do Éden bíblico e de Martin transparece na presença da manutenção da dialética Natureza/Cultura que as narrativas carregam. Desde a queda de Adão e Eva, culpados por querer conhecer além do que foi disposto por Deus, as coisas sempre foram complicadas na relação com o saber e seus produtos escritos. $\bigcirc$ gesto de Caím, o cultivador, de matar Abel, o pastor, abre o caminho na oposição de um mundo que se organiza em cidade, inventa a escrita e, cada vez mais tecnológico, se ilude no domínio da Natureza. $\bigcirc$ orgulho humano de alcançar o conhecimento de Deus traduz-se na tentativa falida de construir a torre de Babel, quando tudo se torna ainda mais difícil na multiplicação das línguas. Sonho humanista será, de fato, recrear uma língua tão universal que sua inscrição coincida com a própria realidade do mundo natural, em que se depositam os signos divinos.

O domínio da Natureza por parte da Cultura torna-se visível no mito da Arca de Noé. O esforço que Noé realiza, guiado por Deus, para organizar o mundo natural realiza-se sob forma de coleção, incompleta, pois faltaram os unicórnios: a universalidade não pertence à humanidade, mas a Deus. Coleção organizada em um espaço cuja arquitetura foi objeto de estudo de muitos teólogos medievais, entre os quais se destaca aquele mesmo Hugo de São Vitor (2001) autor do "Didascalicon" em que se ensina o caminho da leitura.

A Arca de Noé é objeto de um tratado sobre memória, e boa parte da obra é consagrada à discussão sobre o tamanho e a configuração do barco. Designar a divisão dos espaços e a disposição dos animais de forma rigorosa permite depositar e recuperar neles o conhecimento. Modelo de coleção natural, a arca é, ao mesmo tempo, modelo da biblioteca universal, como observa Barthes (2003).

Eis, então, que a biblioteca de um filme blockbuster se torna arca de Noé e torre de Babel congelada, enquanto as potencialidade de Vox como volta ao Éden se multiplicam.

\section{O BIBLIOTECÁRIO DA FICÇÃO E A AUTO- IMAGEM DE UM MODELO PROFISSIONAL: UM PARADOXO FINAL.}

A biblioteca pode tornar-se a meta de um itinerário de conhecimento, onde a busca de uma "ideia de salvação" é destinada a não realizar-se de maneira grandiosa, e o bibliotecário a perder-se em um labirinto paralelo ao da biblioteca, constituído por seus próprios "mapas" desse território. É esse o bibliotecário de "O homem sem qualidades" (Musil, 1999), como bem explica o general Stumm, no capítulo "O general Stumm se infiltra na Biblioteca Pública e colhe experiências 
sobre bibliotecários, serventes de bibliotecas e ordem intelectual".

Percorremos esse colossal tesouro de livros, e posso dizer que não me abalei tanto assim, essas fileiras de livros não são piores do que um desfile de guarnição. [...] Como nosso passeio não acabava nunca, perguntei ao bibliotecário quantos volumes havia nessa biblioteca maluca. Imagine só o que ele respondeu: três milhões e meio de volumes!!! Estávamos, segundo ele, no numero setecentos mil, mas a partir dali fiquei calculando sem parar; vou poupar você disso, mas no ministério calculei mais uma vez com lápis e papel: eu levaria dez mil anos para conseguir o que pretendia! (Musil, 1999, p.328).

Já sobre o bibliotecário do Politécnico de Viena, Musil descreve a sensação de incerteza perante a imensa multidão de livros, a sensação de falta de orientação ligada à consciência de um saber ilimitado que foge a qualquer tentativa de classificação. A biblioteca, grande metáfora do universo, revela, de repente, sua essência:

Você pode dizer que não se precisa ler todos os livros. E eu respondo: também na guerra não se precisa matar cada soldado, mas cada um é necessário. Mas, veja, aí já há alguma coisa errada, pois isso não é verdade; eu perguntei ao bibliotecário! (Musil, 1999, p.328).

Assim, o general Stumm descobre o absurdo de um universo dominado por leis obscuras e inalcançáveis, onde não é permitido encontrar "a ideia mais bonita do mundo", nem o "livro sobre a concretização do essencial". Ainda, a ordem aparentemente perfeita da sala e dos catálogos, tornase mero jogo infinito de espelhos que torna inútil todo esforço do conhecimento; "hospício" onde o cúmulo 160 da lógica, da "bibliografia das bibliografias", do "registro alfabético dos registros alfabéticos" projeta outras tantas salas de catálogos em uma sequência irracional:

Sabe, devo ter manifestado tamanha sede de saber em meus olhos que de repente o cara ficou com medo de que eu o sugasse até o fundo; eu disse mais alguma coisa sobre roteiros de ferrovia que deveriam permitir ligar quaisquer pensamentos e fazer conexões; aí ele ficou incrivelmente cortês e se ofereceu para me levar à sala dos catálogos, embora fosse proibi- do, porque só os bibliotecários podem utilizála. E logo me encontrei no verdadeiro Empíreo da biblioteca. Acredite, tive a sensação de ter entrado no interior de um crânio; nada ao meu redor além de prateleiras com livros, por toda parte escadas para subir, e sobre as prateleiras e mesas nada senão catálogos e bibliografias, a essência do saber, e em nenhum lugar nada para ler, só livros a respeito de livros: tudo com um verdadeiro cheiro de fósforo cerebral, e eu não estou inventando ao dizer que tive a impressão de ter conseguido alguma coisa! Mas, naturalmente, quando o homem quis me deixar sozinho, senti-me esquisito, quase diria que era uma sensação sinistra, devota e sinistra! (Musil, 1999, p.329).

Dividida em loci, conforme a antiga Arte da Memória, a biblioteca de Musil aparenta visualizar um sistema mnemônico, interessante pela associação com a ideia de rede (a ferrovia como prelúdio de uma infovia) entre livros. Todavia, no armazém da memória do século XX desaparece a ilusão de atingir a verdade:

Todos estamos convencidos de que nossa época é mais ou menos a mais organizada que já existiu. [...] mas imagine apenas uma ordem humana total, universal, em suma uma ordem civil perfeita: eu afirmo, essa é a morte pelo frio, a rigidez cadavérica, uma paisagem lunar, uma epidemia geométrica! (Musil, 1999, p.331).

Musil revela o xeque mate cognitivo e existencial perante os limites mas, acima de tudo, ressalta a condenação de instituições desumanas que aniquilam o indivíduo, aparentemente inquieto, nessa biblioteca que se tornou uma fortaleza, Musil retrata o guardião a ela preposto, o bibliotecário:

Senhor general - disse ele - o senhor quer saber como é que conheço cada livro? Posso Ihe dizer: é porque não leio nenhum! [...] $\bigcirc$ segredo de todos os bons bibliotecários é que nunca lêem senão os títulos e índices de conteúdo dos livros que thes são confiados [...] Quem se interessa pelo conteúdo está perdido como bibliotecário! (Musil, 1999, p.331).

Perplexo, o general descobre que o bibliotecário, na verdade, dedica-se, sim, à leitura mas, exclusivamente, dos catálogos que constituem uma 
biblioteca paralela, misteriosa e inacessível tanto quanto a outra. Vale lembrar, como faz ele mesmo, o curriculum do bibliotecário:

Sou professor universitário, professor de biblioteconomia. A biblioteca é uma ciência independente. [...] Quantos sistemas o senhor acredita que existem, general, segundo os quais se colocam, conservam, ordenam os títulos, corrigem nas capas os erros de impressão, dados falsos e assim por diante? (Musil, 1999, p.330)

Michel Melot, iá diretor do Département des Estampes et de la photographie da Bibliothéque National de France e da Bibliothéque Publique $d^{\prime}$ Information du Centre Georges Pompidou e já presidente do Conseil Superieur des Bibliothéques afirma, em seu "La sagesse du bibliothécaire" que "[...] sans illusion sur la capacité a lire tous le livres, le bibliothécaire ne renonce pás à vivre parmi eux et a

\section{REFERÊNCIAS}

BARROS, M.H.T.C. Disseminação da informação. Marília: [s.n.], 2003.

BARTHES, R. Como viver junto: simulações romanescas de alguns espaços cotidianos. São Paulo: Martins Fontes, 2003.

BORGES, M.A.G. O profissional da informação: somatório de formações, competências, e habilidades. In: BAPTISTA, Sofia Galvão; MUELLER, S.P.M. (Org.). Profissional da informação: o espaço de trabalho. Brasília: UnB, 2004.

BRADBURY, R.D. Fahrenheit 451. [S.I. : s.n.], 1953.

BURTON, R. Anatomie de la mélancolie. Paris: Gallimard, 2005.

COELHO, T. (Org.) Dicionário de política cultural: cultura e imaginário. São Paulo: lluminuras/Fapesp, 1997.

DANTE ALIGHIERI. La divina commedia. [2005?]. Disponível em: <http://www.liberliber.it/biblioteca/a/alighieri/ la_divina_commedia/pdf/la_div_p.pdf $>$. Acesso em: 19 dez. 2007.

O DIA depois de amanhã [The day after tomorrow]. Direção de Roland Emmerich. Los Angeles: 20 th Century Fox, 2004. 1 DVD (124 min.): son., color.

FAHRENHEIT 451 [Farenheit 451]. Direção de François Truffaut. Londres: Anglo Enterprises, 1966. 1 DVD (1 $12 \mathrm{~min}$.): son., color.

HUGO DE SÃO VITOR. Didascalicon. Petrópolis: Vozes, 2001.

LONDON, J. Martin Éden. 2004. Disponível em: <http:// www.gutemberg.org/etext/1056>. Acesso em: 04 jan. 2008.

A MÁQUINA do tempo [The time machine]. Direção de: Simon Wells. Los Angeles: Warner Bros. Picture, 2002. 1 DVD (96 min.): son., color.

MARQUETIS, E.M. O profissional da Informação sob o ponto de vista do usuário. In: SOUTO, Leonardo Fernandes (Org.). O les aprivoiser. II sait lire les livres sans les ouvrir" (Melot, 2004, p.9).

Aquilo que nas palavras de Musil é expressão de crítica a um saber que se tornou hermético, fechado, auto-referencial, torna-se perspectiva de um profissional bibliotecário que, por meio das informações de natureza física e técnica, da presença ou ausência de ilustrações, qualidade do papel, da impressão e conhecimento das edições, desempenha o papel de mediação entre o livro e seus leitores. Essa leitura "exterior" atenta, que exclui sistematicamente o conteúdo, sendo definida, sempre por Melot como "sabedoria do bibliotecário", reverte a crítica do século XX às suas bibliotecas, como expressa também por Ortega y Gasset (2006), que previa a proliferação vertiginosa dos livros, a ponto de sufocar o homem como uma vegetação tropical, nas habilidades do profissional modelo. profissional da informação em tempo de mudanças. Campinas: Alínea, 2005.

MELOT, M. La sagesse du bibliothécaire. Paris: L'Oeil Neuf Éditions, 2004.

MUSIL, R. O homem sem qualidades. Rio de Janeiro : Nova Fronteira, 1999.

O NOME da rosa [ll nome della rosa]. Direção de Jean-Jacques Annaud. França/Alemanha/ltália Roma: Cristaldi Film, Neve Constantin Film/Films Ariane, 1986. 1 DVD (132 min.): son., color.

OLIVEIRA, M. (Org.). Ciência da informação e biblioteconomia: novos conteúdos e espaços de atuação. Belo Horizonte: UFMG, 2005.

ORTEGA Y GASSET, J. Missão do bibliotecário. Brasília: Briquet de Lemos, 2006.

STAR Trek. Produção: Gene Roddenberry. Londres: NBC, 1966. 79 episódios (50.min). Elenco: William Shatner; Leonard Nimoy, DeForest Kelley, Nichelle Nichols, James Doohan, George Takei, Walter Koenig. Apresentada no Brasil sob o título: Jornada nas estrelas.

STAR Wars: A guerra dos clones [Star Wars Episode Il: Attack of the clones]. Direção de George Lucas. Londres: Lucas Filmes/JAC Productions, 2002. 1 DVD (142 min.): son., color.

VALENTIM, M.L. (Org.). Formação do profissional da informação. São Paulo: Polis, 2002.

WELLS, H.G. The time machine. 2004. Disponivel em: < http:// www.gutenberg.org/files/35/35.txt>. Acesso em: 04 jan. 2008.

ZAFÓN, C.R. L'ombra del vento. Milão: Mondolibri, 2004. Tradução de: La sombra del viento. 
